\title{
Technological and Ecological Aspects of Disposal of Spent Cutting Fluids
}

\author{
Yuliia Zelenko', Maryna Bezovska', Valeriy Kuznetsov ${ }^{2 *}$, Antonina Muntian ${ }^{1}$ \\ 1 Dnipro National University of Railway Transport named after Academician V. Lazaryan, 49033, Dnirpo, Ukraine \\ 2 Railway Research Institute, ul. Chłopickiego 50, 04-275 Warsaw, Poland \\ * Corresponding author's e-mail: vkuznetsov@ikolej.pl
}

\begin{abstract}
Processing of metals by cutting under modern conditions becomes impossible without the use of effective cutting fluids. The main purpose of cutting fluids is cooling, lubrication of the workpiece processing area. Spent emulsion is a special type of wastewater, very dangerous to the environment, as it contains a large number of persistently emulsified petroleum products. The methods using various surfactants were tested for the cutting fluid disposal. The obtained results allowed proposing a general flow diagram of treatment of spent cutting fluids, as well as a block diagram of their purification. After processing the spent cutting fluids according to the proposed diagram, two products were obtained, namely water and sludge. This technology can be used in metalworking shops of railway enterprises, as well as the enterprises of machine-building, metallurgical and other industries where CFeffluents are formed within the wastewater complex. It will provide both an economic result through the reuse of water and will give a significant environmental effect by minimizing the amount of hazardous waste.
\end{abstract}

Keywords: waste, cutting fluid, surfactant, treatment diagram

\section{INTRODUCTION}

Intensification of the metal machining processes, introduction of high-performance equipment, automated processes, wide use of structural materials lead to the fact that metal cutting becomes impossible without the use of efficient cutting fluids [Zelenko et al., 2014; Zelenko et al., 2016].

The main purpose of cutting fluids is cooling, as well as lubricating the workpiece processing area. This provides a decrease in temperature in the area of cutting and friction and the following positive effects are observed:

- Increased durability of the cutting tool due to decreased temperature and frictional wear;

- Improved quality of processing due to the reduced number of burrs, damage to the treated surfaces, as well as impact of thermal expansion.

As a result of the cutting fluids application, the amount of rejects is reduced; it is possible to increase the cutting modes without losing accuracy.
Cutting fluid is an aqueous emulsion of mineral oil, stabilized by surfactants and various organic additives designed to prevent the premature aging of the emulsion. With use, the fluid loses its technological properties and needs to be replaced with fresh one [Rushikesh \& Dayanand, 2016; Dado et al., 2013].

In the process of using the cutting fluids are prone to be contaminated with:

- the smallest mechanical particles (impurities) released from the oxidized layer of metal, sludge after etching and wear products of metal during etching and cold rolling;

- Free (non-emulsified) oils released from the emulsion as a result of delamination;

- Oils that enter the emulsion system as a result of leaks from mechanical and hydraulic units of metalworking equipment, etc.

At the same time, there is a thermal destruction of organic components of cutting fluids as local temperature in the places of contact of the 
cutting tool and the processed detail can reach $450-500{ }^{\circ} \mathrm{C}$.

Spent cutting fluid is a special type of wastewater that is very dangerous to the environment, as it contains a large number of persistently emulsified petroleum products. Such petroleum products may contain benzo( $\alpha$ )pyrene, furans, dioxins, polychlorinated biphenyls and other highly dangerous compounds that cause adverse effects on the central nervous and cardiovascular systems, endocrine system, reduce the hematological parameters, as well as cause liver and thyroid damage. The used cutting fluid contains $10-30 \mathrm{~g} / 1$ of emulsified oils and a large amount of free oils. The total amount of ether-soluble substances in emulsion wastewater is $20-30 \mathrm{~g} / \mathrm{l}$. Spent cutting fluid belongs to the 3 rd class of danger, the maximum permissible concentration (MPC) of one of the main components of $\mathrm{CF}$ - mineral oil - in the drinking and domestic water use facilities is $5 \mathrm{mg} / \mathrm{m}^{3}$, LD (lethal dose) $50=7000 \mathrm{mg} / \mathrm{kg}$. In this regard, it is necessary to carry out a set of measures to neutralize the spent MPA.

Spent cutting fluids must be neutralized from the most toxic components. The existing methods of neutralizing such emulsions as CF-containing effluents can be divided into three main groups: thermal, physicochemical, biological [Pyza et al., 2018; Shokrani et al., 2012; Okada et al., 2014; Shapoval et al., 2014; Markisova et al., 2013; Davydova \& Tagasov, 2002; Zelenko et al., 2020; Zelen'ko \& Yaryshkina, 2008; Samarska et al., 2020; Peter et al., 2007; Marián et al., 2015; Mirer, 2010; Muszyński \& Łebkowska, 2005; Skerlos, 2013; Gordon, 2004; Najiha et al., 2016].

None of these groups alone can meet the modern requirements for the quality of treated water and the amount of waste generated. The use of traditional chemical and physicochemical methods leads to secondary environmental pollution due to the generation of various wastes. Most methods of disposing of spent CF-containing effluents are either economically inefficient or environmentally unacceptable. Therefore, the problem of cutting fluid disposal remains relevant [Jacyna et al., 2018; Fuks et al., 2004; Zelenko et al., 2019; Boughton \& Horvath, 2004; Choon-Man et al., 2017; Zelenko et al., 2020].

No less important is the task of developing such measures for the purification of cutting fluids, which would allow purifying them and other process fluids to a state that would make possible their reuse at minimal cost.

\section{MATERIALS AND METHODS}

For the disposal of cutting fluids, we tested the methods using various surfactants.

Experimental studies were performed with the fluid of "Unizor-M" brand. It is a concentrate of synthetic universal lubricating and cooling liquid for mechanical processing, which is widely known in Ukraine, also exported to Russia, Belarus, Moldova, and EU countries. It is used in the form of $3-5 \%$ aqueous solution as a universal cutting fluid during abrasive processing of metals and alloys. It is possible to use the working solution of the "Unizor-M" fluid for some operations of deformation treatment, as a low-temperature detergent and as a corrosion inhibitor under certain storage conditions of the treated products.

The samples of the cutting fluid were used on a grinding machine and were rejected. CF before the tests were homogeneous, did not differ in color, no special visual differences were observed.

The following substances were used as main reagents for technological processing:

1. Alkylbenzene sulfonic acid (ABSA) - a substitute for sulfuric acid; the content of sulfuric acid in ABSA is $10 \%$; ABSA allows obtaining various components: triethanolamine salt; alkylbenzene sulfonic acid (TEA-ABSA), sulfonol powder (sodium salt of alkylbenzene sulfonic acid), calcium salt of alkylbenzene sulfonic acid and some others.

2. Asparal F- sodium salts of aspartic acid derivatives; anionic surfactants; mass fraction of the basic substance $-36.0 \pm 2.5 \%$; mass fraction of free hydrate of sodium oxide, $\%$, not more than 1.0; can be used as a collector in the flotation of tin ores, oxidized iron ores at $\mathrm{pH} 2-10$, scheelite, barite, in the concurrent production of fluorite concentrates by flotation of ores of quartz-fluorite-cassiterite type, in the flotation of fluorite from silicate fluorite, also can be used for flotation of complex rare earth ores of different genesis.

3. Cocamidopropyl Betaine - soft surfactant, which is obtained from the use of coconut oil (concentration $30 \%$ ); it is a purifier used in combination with stronger surfactants (sodium lauryl sulfate), compatible with anionic / cationic / nonionic surfactants; reduces the irritating effect of other surfactants (refers to the ingredients of medium risk); in combination with anionic surfactants it becomes a thickener; it can be used as the main surfactant; it also has 
good cleaning and foaming properties.

4. Neonol AF 9-12 is a water-glycol solution of a mixture of anionic and nonionic surfactants, most often used to intensify the oil production, can also be used in the textile, pulp and paper industry, as a means of protection and regulation of plant growth, as a component in composition of lubricating and cooling, hydraulic and other technological fluids, in ferrous metallurgy, as an active basis for technical detergents, raw materials for the synthesis of some types of active basis of textile auxiliary products.

We tested one of the physical methods of purification, namely settling with the additional use of the above-mentioned reagents. Before purification, the cutting fluid was heated, and the optimum temperature to reduce the viscosity was $50-60{ }^{\circ} \mathrm{C}$, which provided faster and more efficient deposition of contaminants. Each of the four reagents was added to the cutting fluid separately. After 30 minutes, the result was recorded.

\section{RESULTS AND DISCUSSION}

In the case of ABSA and Asparal F application, no changes were noted. The use of Cocamidopropyl betaine and Neonol AF 9-12 had a noticeable effect, namely the formation of a precipitate, so these two reagents were given further attention. Specifically, in the experiment with Neonol AF 9-12, we managed to obtain the best result, which qualitatively solved the problem, i.e. minimized the rate of contamination with the release of water, which can be used later after treatment.

Next, we reproduced the Neonol experiment, and the volume of the CF sample was increased.
The result remained the same - the resulting volume of water was $67 \%$ of the volume of spent CF with the amount of Neonol $5 \%$ by weight of the cutting fluid. The results obtained with Neonol and Cocamidopropyl betaine are also shown in Figures 1-2.

According to Figure 3, the spent cutting fluid is heated, then surfactants are added, mixed, settled, water is separated, and the precipitate is sent for dehydration; the resulting sludge is sent for disposal. On the basis of the general flow diagram, we developed the block diagram with the equipment. It is shown in Figure 4.

The flow diagram will work as follows. The contaminated CF is sent to the tank with the heating element and stirrer, then surfactant is added, the amount of which depends on the cutting fluid volume. A dosing pump is used for accurate surfactant dosing. Cutting fluid and surfactant react, as a result the cutting fluid is separated into water and sludge, water is pumped into the purification unit, the sludge is pumped into the decanter, where additional water is released, while the sludge is sent for disposal. The water from the decanter also enters the after-treatment unit.

In order to obtain an additional volume of water contained in the sludge formed during the treatment of cutting fluid, this sludge can be dehydrated. Thus, today the most effective technologies are the methods using precipitating screw centrifuges, frame, belt and chamber filter-presses. The use of screw dehydrators and decanter centrifuges is more advanced, because such equipment for sewage sludge dewatering is compact, consumes low energy, is able to operate automatically and does not require significant operating costs, compared to other methods.

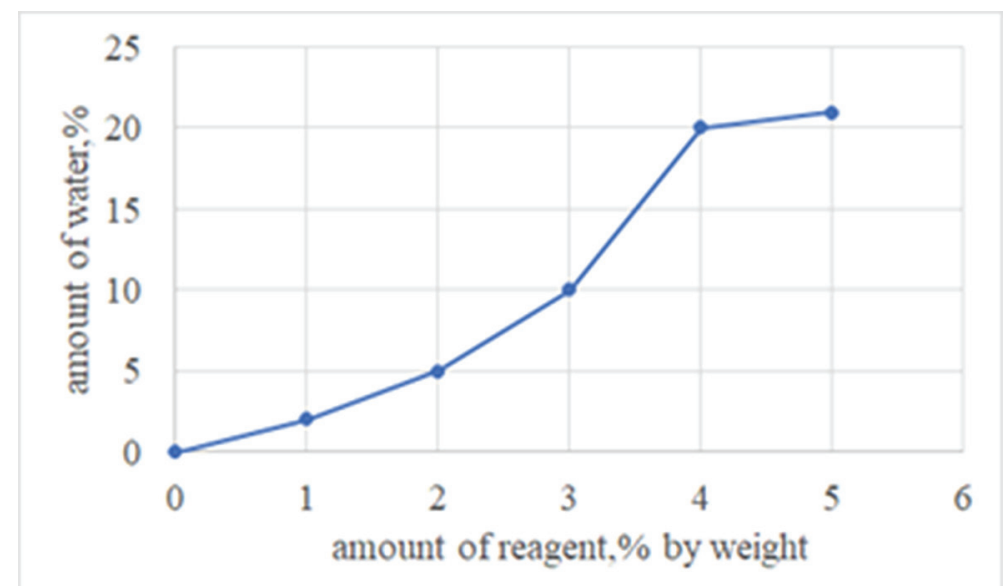

Fig. 1. The results obtained after the use of cocamidopropyl betaine 


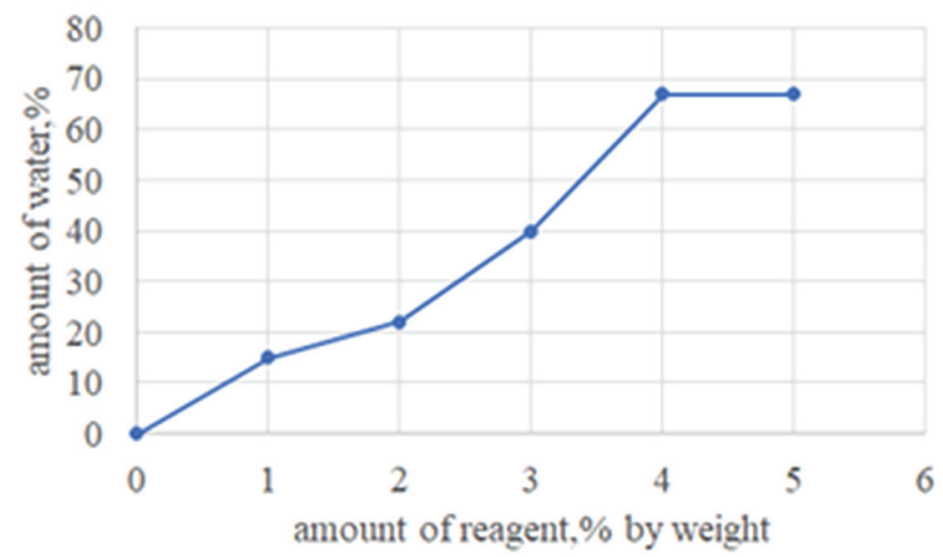

Fig. 2. The results obtained after the use of Neonol AF 9-12

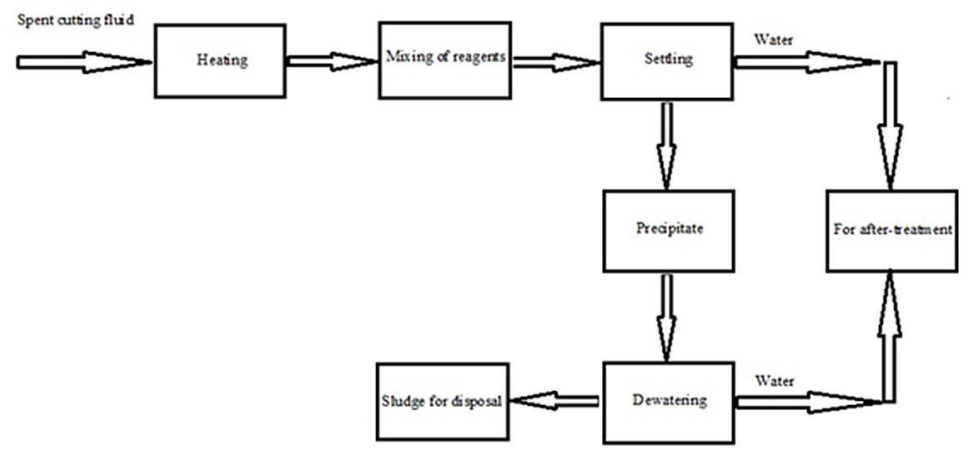

Fig. 3. Flow diagram of treatment of spent cutting fluids using Neonol AF 9-12

1-tankwithheatingelementandstirrer;2-surfactanttank;3-dosingpump;4-after-treatmentunit;5-decanter;6-pump

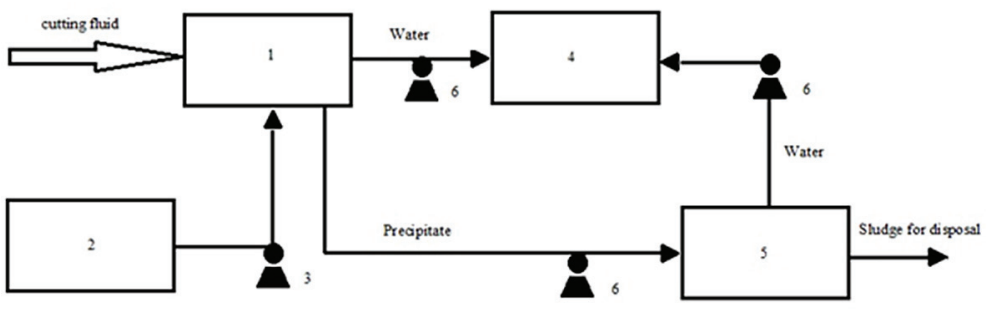

Fig. 4. Block diagram of cutting fluid purification

The water obtained after the spent cutting fluid separation into components is polluted with the remains of mineral oils, mechanical impurity in insignificant quantities; in addition, it may contain remnants of surfactants.

Depending on the wastewater properties, concentration and fractional composition, the following methods can be used to treat wastewater from mechanical impurities: filtration, settling, separation of mechanical particles in the field of action of centrifugal forces, as well as filtration [Zelenko \& Bezovska, 2019; Zelenko et al., 2019].

\section{CONCLUSIONS}

Thus, after processing the spent cutting fluid according to the proposed scheme, we obtain two products, namely water and sludge. After re-treatment, the water can be used in industrial circulation for domestic consumption or for the preparation of a new cutting fluid, and in compliance with the sanitary requirements it can be discharged into the sewerage network of the enterprise or even into reservoirs. 
The removed sludge, as a marketable product, can be sold to the enterprises producing reinforced concrete structures and asphalt.

This technology can be used in metalworking shops of railway enterprises, as well as the enterprises of machine-building, metallurgical and other industries where CF-effluents are formed within the wastewater complex. One of the most promising examples of the use of this technology for the utilization of spent cutting fluid is its introduction at local treatment plants of locomotive and car sheds, as well as at complex waste disposal stations of the railway.

The proposed technology provides a double effect:

- Ecological - by minimizing the amount of waste belonging to hazard class III and the rational use of water resources;

- Economic - due to the reuse of water in the circulating system of water supply and oil products.

\section{REFERENCES}

1. Pyza, D., Jacyna-Gołda, I., Gołda, P., Gołębiowski, P., 2018. Alternative Fuels and Their Impact on Reducing Pollution of the Natural Environment. Rocznik Ochrona Środowiska, Tom 20, cz. 1, 819-836.

2. Shokrani A., Dhokia V., Newman S.T., 2012. Environmentally conscious machining of difficultto-machine materials with regard to cutting fluids. International Journal of Machine Tools \& Manufacture, vol. 57, 83-101

3. Markisova, N.F., Grebenyuk, A.N., Basharin, V.A., 2013. Toxicology of petroleum products: [methodical manual]. St. Petersburg: Nevsky dialect, p. 128 (in Russian)

4. Jacyna, M., Wasiak, M., Lewczuk, K., ChamierGliszczyński, N., Dąbrowski, T., 2018. Decision Problems in Developing Proecological Transport System. Rocznik Ochrona Środowiska, Tom 20, cz. 2, 1007-1025

5. Zelenko, Y., Bezovska, M., 2019. Development of an environmentally friendly scheme for the recovery of used engine oils. New stages of development of modern science in Ukraine and EU countries. Monograph. 3rd ed. Riga, Latvia: "Baltija Publishing": $143-164$

6. Davydova, S. L., \& Tagasov, V. I., 2002. Heavy metals as supertoxicants of the XXI century: [tutorial]. M.: RUDN Publ.H., p. 140 (in Russian)

7. Zelenko, Y., Bezovska, M., Leshchynska, A., Shnaiderman, A., 2019. Disposal of technological sludge of railway infrastructure enterprises. MATEC Web-Conferences 294, 02006

8. Fuks, I.G., Spirkin, V.G., Shabalina, T. N., 2004. Fundamentals of chemmotology. Chemmotology in the oil and gas business: [tutorial]. M .: FGUP Publishing house "Oil and Gas" of the Gubkin Russian State University of Oil and Gas, p. 280 (in Russian)

9. Okada M., Hosokawa A., Asakawa N., Ueda T., 2014. End milling of stainless steel and titanium alloy in an oil mist environment. The International Journal of Advanced Manufacturing Technology, vol. 74, no. 9-12, 1255-1266

10. Shapoval J.M., Kochubei V.V., Suberliak O.V., Poliuzhyn I.P., Kozak M.B., 2014. Development and study of the properties of cutting fluids based on polyvinylpyrrolidone and polyacrylamide. Chemistry, technology of substances and their application. Series of Chemistry, Materials Technology and their Application, vol. 787, 469-474 (in Ukrainian)

11. Zelenko, Yu., Myamlin, S., Sandovskiy, M., 2014. Scientific foundation of management of the environmental safety of oil product turnover in railway transport. D.: Lithograph Publishing House, p. 332

12. Peter Giraltoš, Dušan Maga, Victor Klekovkin, 2007. Ecological aspects of cutting fluids \& minimization of the ecological impacts of cutting fluids Cybernetic Letters, Kopes

13. Zelenko, Yu. V., Tarasova, L. D., Bezovska, M. S., 2016. Increase of the level of ecological safety while handling the used motor oils of railway infrastructure: [monograph]. Dnipro: Lithograph Publ. H., p. 150 (in Ukrainian)

14. Choon-Man Lee, Young-Ho Choi, Jae-Hyeon Ha, Wan-Sik Woo, 2017. Eco-friendly technology for recycling of cutting fluids and metal chips: A review. International Journal of Precision Engineering and Manufacturing-Green Technology volume 4, 457-468

15. Najiha, M. S., Rahman, M. M., Yusoff, A. R., 2016. Environmental Impacts and Hazards Associated with Metal Working Fluids and Recent Advances in the Sustainable Systems: A Review. Renewable and Sustainable Energy Reviews, Vol. 60, 1008-1031

16. Yuliia Zelenko, Maryna Bezovska, Valeriy Kuznetsov, Antonina Muntian, 2020. Resource Saving and Eco-Friendly Technology for Disposal of Used Railroad Engine Oils. Rocznik ochrona środowiska (Annual Set The Environment Protection) $22,171-180$

17. Marián Schwarz, Miroslav Dado, Richard Hnilica, Darina Veverková, 2015. Environmental and Health Aspects of Metalworking Fluid Use. Polish Journal of Environmental Studies 1, vol.24, 37-45

18. Zelen'ko, Y., Yaryshkina, L., 2008. Development of nature protection measures after emergency spills of 
oil products (WIT / Transactions on Ecology and the Environment), 109, 243-247

19. Rushikesh Waydande, Dayanand Ghatge, 2016. Performance Evaluation of Different Types of Cutting fluids in the Machining of hardened steel - a Review; International Journal of Mechanical and Production Engineering, 4(3), 34-39

20. Zelenko Yu, Lunys O, Neduzha L and Steišūnas S, 2019. The assessment of negative impact of oil products on railroad track and rolling stock constructions Proc. of the 23rd Intern. Sci. Conf. Transport Means 2019 pt III (Palanga, Lithuania: Kaunas Univ. of Technology), 1300-1306

21. Mirer F. E., 2010. New Evidence on the Health Hazards and Control of Metalworking Fluids Since Completion of the OSHAAdvisory Committee Report. Am. J. Ind. Med. 53, 792

22. Zelenko Y, Malovanyy M and Tarasova L, 2019. Optimization of heat-and-power plants water purification Chemistry and Chemical Technology, 13(2), 218-223

23. Boughton, B., Horvath, A., 2004. "Environmental assessment of waste oil management methods" Environ. Sci. Technol., 38, 353-358

24. Gordon T., 2004. Metalworking fluid-the toxicity of a complex mixture. J. Toxicol. Environ. Health A 67(3), 209-219

25. Samarska, A., Zelenko, Y., Kovrov, O., 2020. Investigation of Heavy Metal Sources on Railways: Ballast Layer and Herbicides Journal of Ecological Engineering, 21(8), 32-46

26. Dado M., Schwarz M., Hnilica R., 2013. Metalworking Fluid Mist Characterization for the Turning Process: a Preliminary Study. 7th Annual International Conference 2013: Manufacturing Systems Today and Tomorrow. Technical University of Liberec

27. Muszyński A., Łebkowska M., 2005. Biodegradation of Used Metalworking Fluids in Wastewater Treatment. Polish Journal of Environmental Studies, 14(1), 73-79

28. Skerlos S.J., 2013. Cutting Fluids and Their Environmental Impact. Encyclopedia of Tribology, 655-60

29. Zelenko Yu., Bezovska M., Skvireckas R., Neduzha L., 2020. The Impact of Motor Oils Quality on Improving the Reliability in Operation of Traction Rolling Stock. Proceedings of the 24th International Scientific Conference 'Transport Means 2020' Sustainability: Research and Solutions (Part II), Sept. 30 - Oct. 02, 2020, Kaunas, Lithuania, 568-572. 